\title{
Estimation of terrestrial gamma radiation (TGR) dose rates in characteristic geological formations of Jos Plateau, Nigeria
}

\author{
Habu Tela Abba a, c, ${ }^{*}$, Wan Muhammad Saridan Wan Hassan a, Muneer Aziz Saleh b, Abubakar \\ Sadiq Aliyu ${ }^{\mathrm{d}}$, Ahmad Termizi Ramli a \\ a Department of Physics, Universiti Teknologi Malaysia, Skudai - 81310, Johor, Malaysia \\ ${ }^{b}$ Department of Energy Engineering, Faculty of Chemical and Energy Engineering, Universiti Teknologi Malaysia, Skudai - 81310, Johor, Malaysia \\ c Department of Physics, Yobe State University Damaturu, Nigeria \\ d Department of Physics, Federal University Lafia, Nigeria \\ *Corresponding author: wmsaridan@utm.my
}

\section{Article history}

Received 1 February 2017

Accepted 27 October 2017

\begin{abstract}
A study was conducted to estimate the terrestrial gamma radiation (TGR) dose rates due to the natural radionuclides ${ }^{238} \mathrm{U},{ }^{232} \mathrm{Th}$ and ${ }^{40} \mathrm{~K}$ in the characteristic geological formations of Jos Plateau. A total of 51 surface soils samples from all the geological units were collected and measured using high-resolution gamma ray spectrometry system. From the measured activity concentrations of ${ }^{238} \mathrm{U}$, ${ }^{232} \mathrm{Th}$ and ${ }^{40} \mathrm{~K}$, TGR dose rates in air outdoors $1 \mathrm{~m}$ above the ground surface, were estimated to be in the range of $36 \mathrm{nGy} \mathrm{h} \mathrm{h}^{-1}$ to $456 \mathrm{nGy} \mathrm{h} \mathrm{h}^{-1}$, depending on the geological formation, with an overall mean value of $143 \mathrm{nGy} \mathrm{h}^{-1}$. The estimated mean value is by a factor of two higher than the world average value of $59 \mathrm{nGy} \mathrm{h}^{-1}$. Geological formation G8 (younger granites) appeared to have the highest mean TGR dose rate while G7 (sandstone, clay and shale) show the lowest mean TGR dose rate. The results of this study inferred that, TGR dose rates outdoors for Jos Plateau varies with the diversity of geological formations and is significantly contributed by ${ }^{232} \mathrm{Th}$. An isodose map for TGR dose rates due to natural sources was also plotted using ArcGIS software. The data here presented can be used to evaluate public radiation dose and can be useful for geochemical exploration.
\end{abstract}

Keywords: Geological formation, Gamma spectrometry, TGR dose rate, isodose map, Jos Plateau.

(c) 2017 Penerbit UTM Press. All rights reserved

\section{INTRODUCTION}

Natural environmental radiation mainly arises from primordial and cosmogenic radioisotopes. Radionuclides formed due to cosmic activities in the earth's atmosphere such as ${ }^{22} \mathrm{Na},{ }^{3} \mathrm{H},{ }^{14} \mathrm{C}$ and ${ }^{7} \mathrm{Be}$ are known as cosmogenic radionuclides (Tzortzis et al., 2003). Radionuclides with half-lives comparable with the age of the earth (Primordial) e.g ${ }^{40} \mathrm{~K}$ and decay series of ${ }^{238} \mathrm{U}$ and ${ }^{234} \mathrm{Th}$ within the soils are the largest contributors to the terrestrial background radiation (Dragović et al., 2006).

Human being are continuously expose with or without their consent to radiation from the cosmic source and terrestrial radionuclides occurring in trace amount in all ground formations (Directive, 1996). Specific levels of terrestrial gamma radiation (TGR) from soils are related to the type of rocks or geological formations from which the soils are derived (Tzortzis, et al., 2003). Therefore, environmental TGR dose rates primarily depends on geological make-up, chemical contents and geographical conditions of the location (Florou and Kritidis, 1992). Granitic type of igneous rocks is found to be associated with higher TGR dose rates compared to low-grade metamorphic and sedimentary rocks (UNSCEAR, 2000). However, some shale and phosphate rocks are relatively rich in natural radionuclides (UNSCEAR, 1993).

Measurement of TGR dose rates have received global interest and led to extensive survey in many countries (UNSCEAR, 2008). Baseline data on TGR dose rate is required for many reasons as reported by several authors (Al-Jundi, 2002; Ramli, 1997; Saleh et al., 2013; Tzortzis, et al., 2003). Despite the global interest, radioactivity levels and gamma radiation for most of Nigerian environment has not been established.

At the outset of this study, existing literatures indicated that there is a data gap to investigate the contribution of terrestrial radionuclides in characteristic geological formations of Jos Plateau to the total terrestrial gamma radiation dose rates. Therefore, the current study aimed to evaluate the contribution of each geological formation to the terrestrial gamma radiation dose rates in Jos Plateau based on the specific activity concentrations of ${ }^{238} \mathrm{U},{ }^{232} \mathrm{Th}$ and ${ }^{40} \mathrm{~K}$ in soil samples. The data presented here, is expected to serve as a reference-data records on environmental gamma dose rates for the area which could be used for future investigation and monitoring of environmental background radiations. It could also be used to ascertain the possible changes in the levels of background gamma radiation due nuclear power plant accidents (e.g. the recent Fukushima accident), nuclear atmospheric weapon testing, industrial and other human activities.

\section{EXPERIMENTAL}

\section{Materials and methods}

\section{The study area}

The area Jos Plateau, is geographically situated between the latitudes of $8^{\circ} 30^{1}-10^{\circ} 10^{1} \mathrm{~N}$ and longitudes of $8^{\circ} 20^{1}-9^{\circ} 30^{1} \mathrm{E}$ on an 
altitude of $1100 \mathrm{~m}$ above sea level in the north-central region of Nigeria (Hassan et al., 2015; Olise et al., 2014). The climate is classified as tropical rainy characterised with the wet and dry type of weather (Olowolafe, 2008). The study area consist of nine local government areas (LGAs) with a total population of 1933505 (NPC, 2006).

Jos Plateau has attracted a lot of researchers' attention because of its substantial deposits of valuable minerals such as tin and columbite in commercial quantity. These minerals are associated with high contents of naturally occuring radiactive materials (NORMs). There are eight lithological formations classified under three geological groups. These includes: Younger granite ring complexes, tertiary basaltic volcanic and Precambrian basement complex rocks of north central Nigeria (Macleod et al., 1971). The descriptions of the geological types and the digitized map are presented in Table 1 and Figure 1, respectively (NGSA, 1956).

Table 1 Geological formations of the study area (NGSA, 1956)

\begin{tabular}{lll}
\hline Code & Geological Name & Description/Composition \\
\hline G1 & $\begin{array}{l}\text { Undifferentiated } \\
\text { basement complex } \\
\text { with pebble beds }\end{array}$ & Metamorphosed Pre-Cambrian \\
& sedimentary and volcanic rocks.
\end{tabular}

G2 Fine and medium grained Biotite

G3 Older Granite

G4 Rhyolite

G5

Older Basalt of Jos

G6

Newer Basalt and trachyte

G7

Sandstone, sandy clay and shale

G8
Dark phyllosilicate mica mineral and medium-grade metamorphic rock

Mostly felsic acidic intrusive igneous rock.

\begin{abstract}
Fine-grained porphyritic igneous rock dominated by phenocrysts $(60 \%)$ and quartz $(40 \%)$ in groundmass.
\end{abstract}

Fine-grained, igneous rock.

Occurs as cones and lavas clay overlaid by a thick cap of lateritic ironstone.

composed of medium to coarse grained sandstone covered by sediments

composed coarse grained Biotite microgranites and some basic rocks.

\section{Samples collection and preparation}

Soil samples were collected across the geological formations of the area for radiometric analysis. For each geological formation, certain number of soils were collected. At each sampling location, samples were obtained at a depth of $1-3 \mathrm{~cm}$ from four different points, thoroughly mixed together to obtain a representative sample for that location. A total of 51 soil samples were collected, which covered the eight geological formations of the study area (Fig. 1). To estimate the true natural TGR dose rate at each location, samples were collected from undisturbed open spaces far away from public structures (Jibiri and Bankole, 2006). Coordinates of the sampling locations were recorded by Global Positioning System (GPS) device (Garmin Corporation, 2008). Labelled polythene bags were used to packed the soil samples and thereafter transported to laboratory.

The samples were dried to a constant weight in an oven at $110^{\circ} \mathrm{C}$ for $24 \mathrm{hrs}$ and sieved through a $0.2 \mathrm{~cm}$ mesh-sized sieve to remove stones, pebbles and other micro-impurities. The homogenized samples were then weighted and packed into a standard $500 \mathrm{~mL}$ Marinelli beakers and stored for about thirty days before analysis to ensure secular equilibrium between radium and its daughter nuclides (Mollah et al., 1987; Saleh et al., 2013a).

The experiments was carried out at Nuclear Physics Laboratory of the Department of Physics, Universiti Teknologi Malaysia, using a highresolution gamma-ray spectrometry counting system. Fig. 2 shows the locations where soil samples were picked.

\section{Gamma spectrometry analysis}

Soil samples were measured for 6 hours using a coaxial high purity germanium (HPGe) detector (GC2018-7500 SL) with a efficiency of $20 \%$ relative to a $7.62 \mathrm{~cm} \times 7.62 \mathrm{~cm} \mathrm{NaI}$ (Tl) detector and a resolution of $1.8 \mathrm{keV}$ for the $1332 \mathrm{keV}$ gamma ray emission of ${ }^{60} \mathrm{Co}$, Genie 2000 software was used to analysed the energy spectra from the gamma emitting radioanuclides. At equilibrium, the energy peaks considered in the present analysis of the measured gamma-ray spectra are: ${ }^{214} \mathrm{~Pb}(352 \mathrm{keV})$ and ${ }^{214} \mathrm{Bi}(609)$, for ${ }^{238} \mathrm{U}$ and ${ }^{208} \mathrm{Tl}(583.1 \mathrm{keV})$ and ${ }^{228} \mathrm{Ac}(911.2 \mathrm{keV})$, for ${ }^{232} \mathrm{Th}$ and that of ${ }^{40} \mathrm{~K}$ was determined directly from it energy emission of $1461.8 \mathrm{keV}$. The background at the laboratory site was determined using an empty Marinelli beaker under the same conditions of measurements. Background count was subtracted from the measured gamma peak of each sample. The value of Minimum Detectable Activity (MDA) was calculated to be $13 \pm 2 \mathrm{~Bq} \mathrm{~kg}^{-1}$ for ${ }^{40} \mathrm{~K}, 1 \pm 02 \mathrm{~Bq} \mathrm{~kg}^{-1}$ for ${ }^{238} \mathrm{U}$ and $2 \pm 07 \mathrm{~Bq} \mathrm{~kg}^{-1}$ for ${ }^{232} \mathrm{Th}$.

\section{Calculation of activity concentrations}

Following the spectrum analysis, specific activity of each radionuclide measured was calculated using equation 1(Ademola and Farai, 2006; Isinkaye, 2013).

$$
C\left(B q k g^{-1}\right)=\frac{C_{n}}{\varepsilon p_{\gamma} M_{s}}
$$

where, $C$ is the specific activity concentration of the radionuclide in the sample, $C_{n}$ is the count rate for the corresponding energy peak, $\varepsilon$ is the efficiency of the detector at the specific gamma ray energy, $P_{\gamma}$ is the absolute transition probability of the specific $\gamma$-ray and $M s$ is the mass of the sample in $\mathrm{kg}$.

\section{Estimation of TGR dose rate}

Assuming the contribution from the radionuclide ${ }^{137} \mathrm{Cs}$ is considered negligible, absorbed gamma dose rate in air at $1 \mathrm{~m}$ above the ground surface for the uniform distribution of ${ }^{238} \mathrm{U},{ }^{232} \mathrm{Th}$ and ${ }^{232} \mathrm{~K}$ was estimated based on the guidelines provided by UNSCEAR (2008) and was estimated by equation 2 (Akiba et al., 2012) .

$$
\mathrm{D}_{\mathrm{R}}=\left(0.462 A_{U}+0.604 A_{T h}+0.0417 A_{K}\right) \mathrm{nGy} \mathrm{h}^{-1}
$$

where, $0.462,0.604$ and 0.0417 are the activity concentration to dose rate conversion factors of ${ }^{238} \mathrm{U},{ }^{232} \mathrm{Th}$ and ${ }^{40} \mathrm{~K}$, respectively (UNSCEAR, 1998), and $A_{T h}, A_{U}$ and $A_{K}$ are the average activity concentrations of ${ }^{232} \mathrm{Th},{ }^{238} \mathrm{U}$ and ${ }^{40} \mathrm{~K}$ in $\mathrm{Bq} / \mathrm{kg}$, respectively.

\section{RESULTS AND DISCUSSION}

The statistical summarry for the activity concentrations of the naturally occurring radionuclides ${ }^{238} \mathrm{U},{ }^{232} \mathrm{Th}$ and ${ }^{40} \mathrm{~K}$ determined in soils samples collected from all the geological units of Jos plateau are presented in Table 2. About $50 \%$ of the activity concentrations of ${ }^{238} \mathrm{U}$ ranged between $81-98 \mathrm{~Bq} \mathrm{~kg}^{-1}$, while $75 \%$ ranged between 188 $457 \mathrm{~Bq} \mathrm{~kg}^{-1}$ for ${ }^{232} \mathrm{Th}$ and $123-1005 \mathrm{~Bq} \mathrm{~kg}^{-1}$ for ${ }^{40} \mathrm{~K}$, respectively. The arithmetic mean values computed from all the soil samples are 88, 157 and $215 \mathrm{~Bq} \mathrm{~kg}^{-1}$ for $\mathrm{U}$, Th and $\mathrm{K}$, respectively while the mean values derived from all data available worldwide (UNSCEAR, 2008) are 40, 45 and $400 \mathrm{~Bq} \mathrm{~kg}^{-1}$, respectively. This revealed that the mean activity concentration from the naturally occurring radionuclides measured in Jos Plateau are higher than the corresponding values obtained worldwide for ${ }^{238} \mathrm{U}$ and ${ }^{232} \mathrm{Th}$ and lower for ${ }^{40} \mathrm{~K}$.

The TGR dose rates estimated from the measured activity of ${ }^{238} \mathrm{U},{ }^{232} \mathrm{Th}$ and ${ }^{40} \mathrm{~K}$ for this study was found to be in the range of 36 $n G y h^{-1}$ to $456 \mathrm{nGy} \mathrm{h}^{-1}$ with overall mean value of $143 \mathrm{nGy} \mathrm{h}^{-1}$, which is by a factor of two higher than the corresponding worldwide average value of $59 \mathrm{nGy} \mathrm{h}^{-1}$ (UNSCEAR, 2000). Frequency distribution curve of the dose rates is represented by a histogram as shown in Figure 3, where most of the dose rates estimated ranged between 85$125 \mathrm{nGy} \mathrm{h}^{-1}(25 \%)$. 


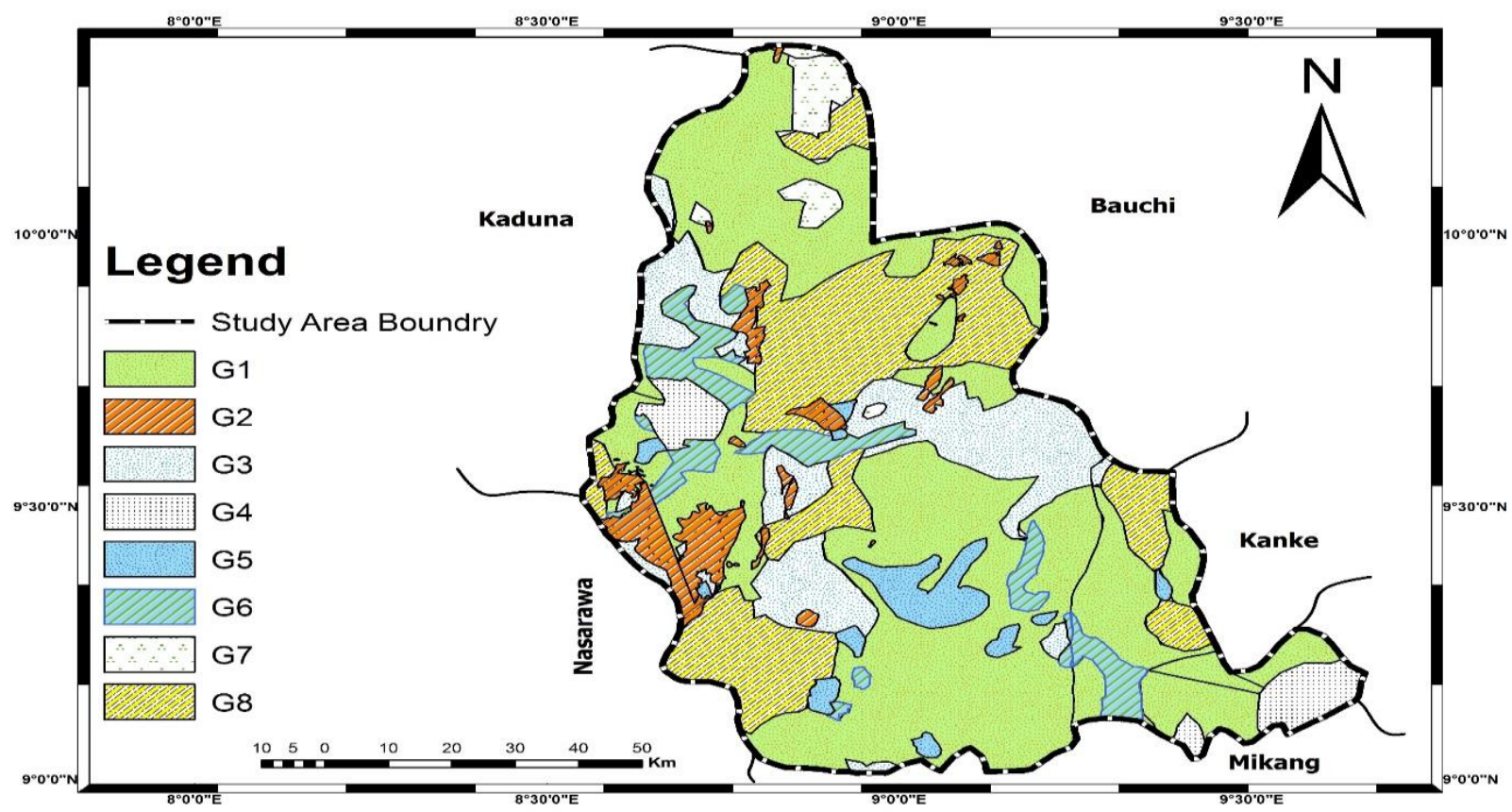

Fig. 1 Geological formations of the study area (NGSA, 1956).

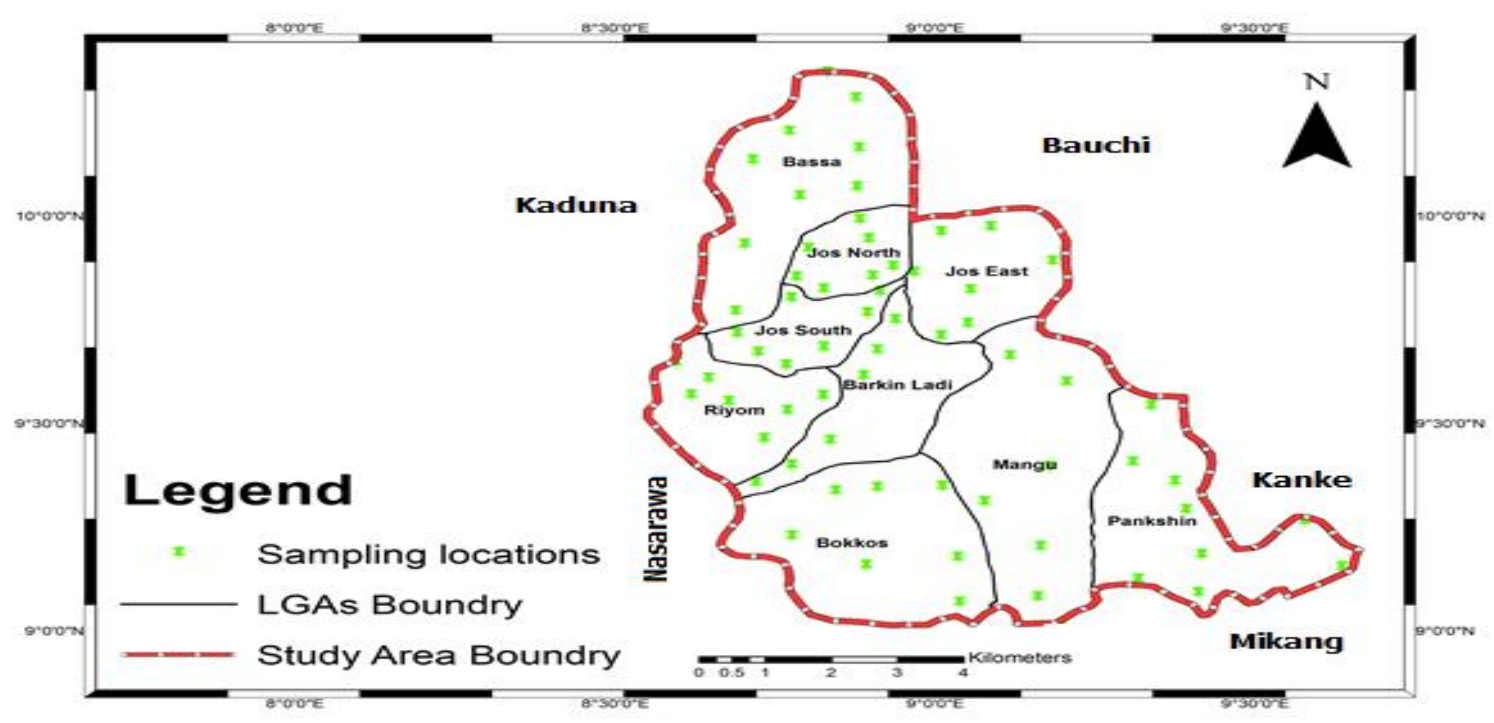

Fig. 2 Sampling locations.

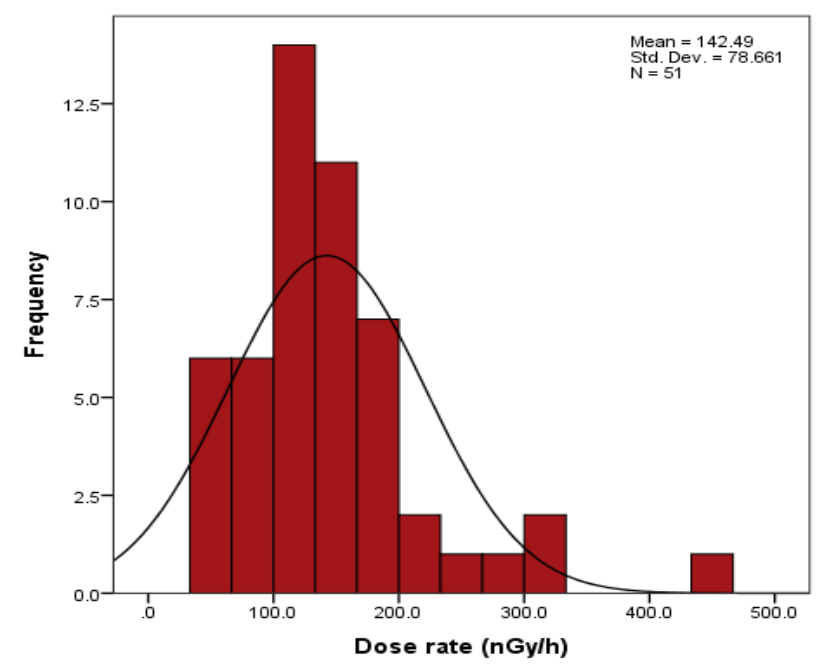

Fig. 3 TGR dose rates frequency distribution curve.

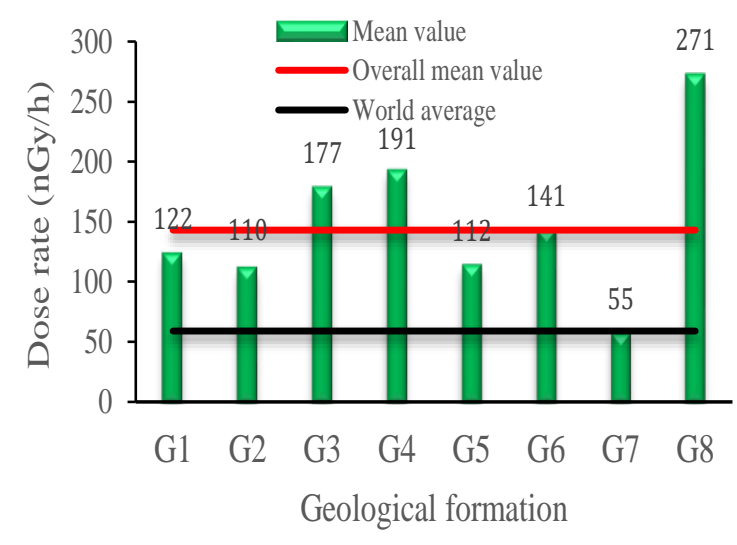

Fig. 4 Mean dose rate for each geological formation. 
Table 2. Statistics for the activity concentrations of ${ }^{238} \mathrm{U},{ }^{232} \mathrm{Th}$ and ${ }^{40} \mathrm{~K}$

\begin{tabular}{cccc}
\hline Statistics & ${ }^{238} \mathbf{U}\left(\mathbf{B q ~} \mathbf{~ g ~}^{-1}\right)$ & ${ }^{232} \mathbf{T h}\left(\mathbf{B q ~}_{\mathbf{~ g}}{ }^{-1}\right)$ & ${ }^{{ }^{40}} \mathbf{K}\left(\mathbf{B q ~} \mathbf{~ g ~}^{-1}\right)$ \\
\hline Mean & 88 & 157 & 215 \\
Range & $27-327$ & $34-457$ & $43-1055$ \\
Std. Error & 6 & 13 & 32 \\
Std. Dev. & 46 & 92 & 232 \\
Mode & 85 & 215 & 280 \\
Median & 81 & 132 & 123 \\
95\% conf. interval & $75-100$ & $131-183$ & $149-280$ \\
\hline
\end{tabular}

The mean TGR for each geological formation is presented in Figure 4. It can be seen from the Figure, tThat he highest mean TGR dose rate is associated with geological type G8 (Younger granites) which is reported to be relatively rich in $\mathrm{U}$ and $\mathrm{Th}$ radionuclides contents in its mineral uraninite, monazite and carnotite (UNSCEAR, 2000) compared to low-grade metamorphic and sedimentary rocks (Tzortzis, et al., 2003). TGR dose rates for the Younger granites ranged between 185 and $456 \mathrm{nGy} \mathrm{h}^{-1}$, with a mean value of $271 \mathrm{nGy} \mathrm{h}^{-1}$. This result agrees with a similar work conducted by Ramli et al. (2005), who also observed higher dose rates over granitic rocks of Melaka in Malaysia. The mean value of $271 \mathrm{nGy} \mathrm{h}^{-1}$ obtained here is found to lower than the value obtained for granitic areas of Melaka, which was more than $350 \mathrm{nGy} \mathrm{h}^{-1}$ (Ramli, et al., 2005). However, the mean value is higher than that reported by Garba et al. (2015) of $209 \mathrm{nGy} \mathrm{h}^{-1}$ in Kelantan for the same geological formation.

The lowest mean value of TGR dose rate was $55 \mathrm{nGy} \mathrm{h}^{-1}$, with ranges of values from 36 to $85 \mathrm{nGy} \mathrm{h}^{-1}$ was observed to be associated with G7 geological type (sandstone, clay and shale) which belong to a sedimentary rock. Sedimentary and low-grade metamorphic rocks are identified to contribute to low dose rates (Sanusi et al., 2014). This value is comparatively higher than the value of $8.7 \mathrm{nGy} \mathrm{h}^{-1}$ reported by Tzortzis et al. (2004) for sedimentary rocks of Cyprus. The mean TGR dose rates for the other geological formations of Jos plateau ranged between $110 \mathrm{nGy} \mathrm{h}^{-1}$ and $191 \mathrm{nGy} \mathrm{h}^{-1}$.

The contributions of ${ }^{238} \mathrm{U},{ }^{232} \mathrm{Th}$ and ${ }^{40} \mathrm{~K}$ to the total TGR dose rates for the study area is shown in Figure 5. ${ }^{232} \mathrm{Th}(66 \%)$ was found to contribute the the highest to the gamma dose rate in the area. This is because ${ }^{232} \mathrm{Th}$ is insoluble and 3-4 times in natural environment compared to ${ }^{238} \mathrm{U}$ (Ravisankar et al., 2015) and is the most abundant radionuclide in the mineral monazite associated with the granitic basement complex formations which underlain the largest land area of the area under investigation. ${ }^{40} \mathrm{~K}$ contributes the least. In general, the results of this study show that, TGR dose rates outdoor $1 \mathrm{~m}$ above soil surface for Jos Plateau varies with the diversity of geological formations of the area and is significantly contributed by ${ }^{232} \mathrm{Th}$.

Contribution of ${ }^{238} \mathrm{U},{ }^{232} \mathrm{Th}$, and ${ }^{40} \mathrm{~K}$ to the total TGR dose rate

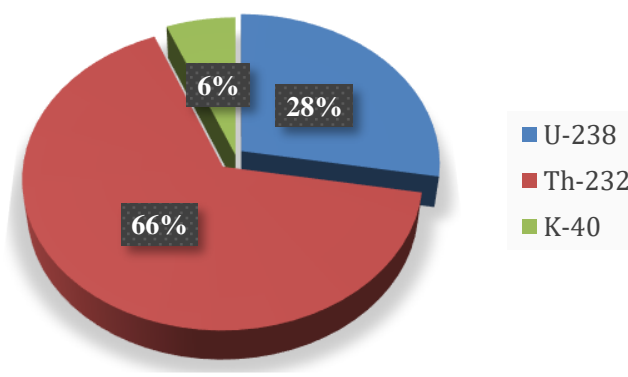

Fig. 5 TGR dose rates contribution of ${ }^{238} \mathrm{U},{ }^{232} \mathrm{Th}$, and ${ }^{40} \mathrm{~K}$ in Jos Plateau.

The coordinates of the sampling locations and the corresponding TGR dose rate values were used to produced an isodose map for gamma radiation exposure rates for the study area using ArcGIS software (Fig. 6). It can be seen that, areas around Jos South, Jos North and Barkin Ladi LGAs appeared to have the higher dose rates. These areas are predominantly underlain by igneous rocks of granitic and basaltic compositions. Areas around Mangu and Pankshin LGAs show TGR dose rates of lower values, this is due to the fact that the areas are underlain by sedimentary rocks such as sandstone, clay and shale.

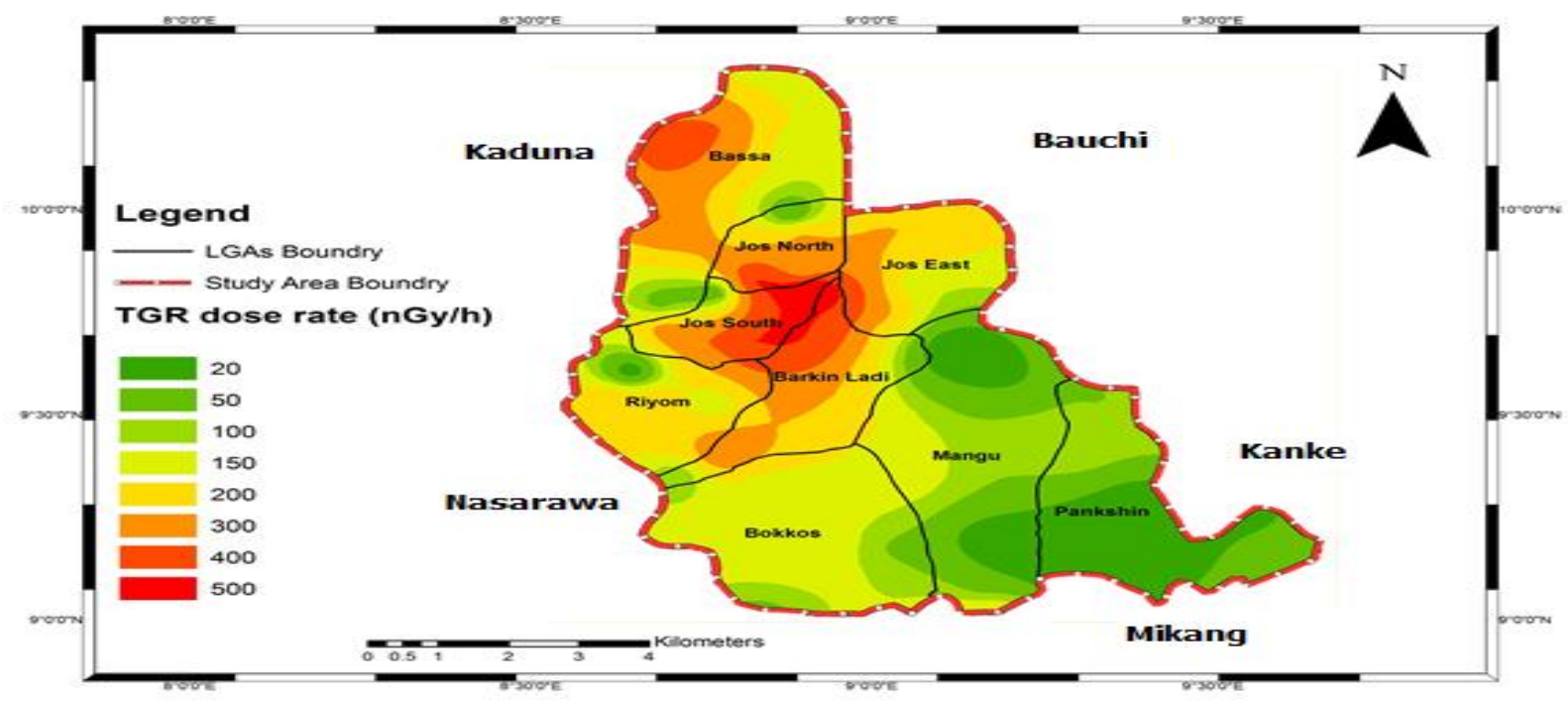

Figure 6 Isodose map of the TGR dose rates. 


\section{CONCLUSION}

Gamma spectrometry technique was used to measure the concentrations of ${ }^{238} \mathrm{U},{ }^{232} \mathrm{Th}$ and ${ }^{40} \mathrm{~K}$ in soil samples collected across the geological characteristics of Jos plateau. TGR dose rates in air outdoors $1 \mathrm{~m}$ above the ground surface is estimated from the specific activity concentrations and was found to be in the range of $36 \mathrm{nGy} \mathrm{h}^{-1}$ to $456 \mathrm{nGy} \mathrm{h}^{-1}$, with an overall mean value of $143 \mathrm{nGy} \mathrm{h}^{-1}$. The estimated mean value is two times higher than the world average value of $59 \mathrm{nGy} \mathrm{h}^{-1}$. Among the geological formations present, Younger granites (igneous rocks) presents the highest dose rates. The lowest TGR dose rates was observed in areas of sandstone, clay and shale (sedimentary rocks). The results also revealed that TGR dose rates for Jos Plateau varies with the diversity of the existing geological characteristics and is significantly contributed by radionuclides ${ }^{232} \mathrm{Th}$ compared to ${ }^{238} \mathrm{U}$ and ${ }^{40} \mathrm{~K}$. The data presented here is expected to serve as reference-data records which can used to evaluate public dose. It can also be used for geochemical exploration and can be useful towards producing radiological map for Nigeria.

\section{ACKNOWLEDGEMENT}

This work is conducted with financial support from the Ministry of Science, Technology and Innovation (MOSTI), Malaysia (Grant No. R.J130000.7926.4S109).The authors also wish to thank Universiti Teknologi Malaysia for providing various facilities and opportunities.

\section{REFERENCES}

Ademola, J. and Farai, I. (2006). Gamma activity and radiation dose in concrete building blocks used for construction of dwellings in Jos, Nigeria. Radiation Protection Dosimetry. 121(4), 395-398.

Akiba, S., Derin, M. T., Vijayagopal, P., Venkatraman, B., Chaubey, R. C. and Gopinathan, A. (2012). Radionuclides and Radiation indices of high background radiation area in Chavara-Neendakara Placer Deposits (Kerala, India). PLoS ONE. 7(11), e50468.

Al-Jundi, J. (2002). Population doses from terrestrial gamma exposure in areas near to old phosphate mine, Russaifa, Jordan. Radiation Measurements. 35(1), 23-28.

Chiozzi, P., Pasquale, V. and Verdoya, M. (2002). Naturally occurring radioactivity at the Alps-Apennines transition. Radiation Measurements. $35(2), 147-154$

Directive, C. (1996). Council directive 96/29/Euratom of 13 May 1996 laying down basic safety standards for the protection of the health of workers and the general public against the dangers arising from ionizing radiation. Official Journal of European Communities. 39(L159), 1-114.

Dragović, S., Janković, L., Onjia, A. and Bačić, G. (2006). Distribution of primordial radionuclides in surface soils from Serbia and Montenegro. Radiation measurements. 41(5), 611-616.

Florou, H. and Kritidis, P. (1992). Gamma radiation measurements and dose rate in the coastal areas of a volcanic island, Aegean Sea, Greece. Radiation Protection Dosimetry. 45(1-4), 277-279.

Garba, N. N., Ramli, A. T., Saleh, M. A., Sanusi, S. M. and Gabdo, H. T. (2015). Radiological mapping of Kelantan, Malaysia, using terrestrial radiation dose rate. Isotopes in Environmental and Health Studies. 1-5.

Garmin Corporation (2008). GPS 12XL Personal Navigator, Operator's manual \& Reference.. https://www.garmin.com/en-US/

Hassan, A., Raji, B., Malgwi, W. and Agbenin, J. (2015). The basaltic soils of Plateau State, Nigeria: Properties, classification and management practices. Journal of Soil Science and Environmental Management. 6(1), $1-8$.

Isinkaye, M. (2013). Natural radioactivity levels and the radiological health implications of tailing enriched soil and sediment samples around two mining sites in Southwest Nigeria. Radiation Protection and Environment. $36(3), 122$.
Jibiri, N. and Bankole, O. (2006). Soil radioactivity and radiation absorbed dose rates at roadsides in high-traffic density areas in Ibadan metropolis, southwestern Nigeria. Radiation protection dosimetry. 118(4), 453-458.

Macleod, W. N., Turner, D. C. and Wright, E. P. (1971). The Geology of Jos Plateau. Bulletin Geological Survey of Nigeria. 32, 12-47.

Mollah, A., Rahman, M., Koddus, M., Husain, S. and Malek, M. (1987). Measurement of high natural background radiation levels by TLD at Cox's Bazar coastal areas in Bangladesh. Radiation Protection Dosimetry. 18(1), 39-41.

NGSA (1956). Geological formations of Jos Plateau, Naraguta (sheet 168): . Prepared British Government's Dept. of Technical Co-operation Under the Special commonwealth African Assistance Plan. Bases Map prepared from D. C. S 30 by Director of Federal Survey, Nigeria, 1956.

NPC (2006). National population Commission (NPC):. Provisional of 2006

Census Results. https://www.jstor.org/stable/25434601?seq=1\#page_scan_tab_contents

Olise, F. S., Oladejo, O. F., Almeida, S. M., Owoade, O. K., Olaniyi, H. B. and Freitas, M. C. (2014). Instrumental neutron activation analyses of uranium and thorium in samples from tin mining and processing sites. Journal of Geochemical Exploration. 142, 36-42.

Olowolafe, A. E. (2008). Land use effects on the properties of an Alfisol on the Jos Plateau, Nigeria. GeoJournal. 71(2-3), 83-91.

Ramli, A. T. (1997). Environmental terrestrial gamma radiation dose and its relationship with soil type and underlying geological formations in Pontian District, Malaysia. Applied Radiation and Isotopes. 48(3), 407412.

Ramli, A. T., Sahrone, S. and Wagiran, H. (2005). Terrestrial gamma radiation dose study to determine the baseline for environmental radiological health practices in Melaka state, Malaysia. Journal of Radiological Protection. 25(4), 435.

Ravisankar, R., Chandramohan, J., Chandrasekaran, A., Jebakumar, J. P. P., Vijayalakshmi, I., Vijayagopal, P. and Venkatraman, B. (2015). Assessments of radioactivity concentration of natural radionuclides and radiological hazard indices in sediment samples from the East coast of Tamilnadu, India with statistical approach. Marine Pollution Bulletin. 97(1), 419-430.

Saleh, M. A., Ramli, A. T., Alajerami, Y. and Aliyu, A. S. (2013). Assessment of environmental $226 \mathrm{Ra}, 232 \mathrm{Th}$ and $40 \mathrm{~K}$ concentrations in the region of elevated radiation background in Segamat District, Johor, Malaysia. Journal of environmental Radioactivity. 124, 130-140.

Saleh, M. A., Ramli, A. T., Alajerami, Y., Aliyu, A. S. and Basri, N. A. B. (2013a). Radiological study of Mersing District, Johor, Malaysia. Radiation Physics and Chemistry. 85, 107-117.

Sanusi, M., Ramli, A., Gabdo, H., Garba, N., Heryanshah, A., Wagiran, H. and Said, M. (2014). Isodose mapping of terrestrial gamma radiation dose rate of Selangor state, Kuala Lumpur and Putrajaya, Malaysia. Journal of Environmental Radioactivity. 135, 67-74.

Tzortzis, M., Svoukis, E. and Tsertos, H. (2004). A comprehensive study of natural gamma radioactivity levels and associated dose rates from surface soils in Cyprus. Radiation Protection Dosimetry. 109(3), 217-224.

Tzortzis, M., Tsertos, H., Christofides, S. and Christodoulides, G. (2003). Gamma radiation measurements and dose rates in commercially-used natural tiling rocks (granites). Journal of Environmental Radioactivity. 70(3), 223-235.

UNSCEAR (1993). Sources and effects ofionizing radiation. Report to General Assembly, with Scientific Annexes. New York: United Nations, http://www.unscear.org/unscear/en/publications/1993.html

UNSCEAR (1988). United Nation Scientific Commitee on the Effect of Atomic Radiation. Sources, Effects and Rsik of Ionizing Radiation. New York. http://www.unscear.org/unscear/en/publications/1988.html

UNSCEAR (2000). Sources and effects of ionizing radiation: UNSCEAR 1993 report to the General Assembly with scientific annexes/United Nations Scientific Committee on the Effects of Atomic Radiation. New York: United Nations. http://www.unscear.org/unscear/en/publications/2000_1.html

UNSCEAR (2008). Sources and effects of ionizing radiation. United Nations Scientific Committee on the Effects of Atomic Radiation. New York. http://www.unscear.org/unscear/en/publications/2008_1.html 